\title{
MANAJEMEN PENDIDIKAN PADA PEMENTASAN WAYANG KULIT
}

\section{Subianto Karoso}

Jurusan Sendratasik FBS UNESA

\section{Abstract}

Leather puppet wltich is playe. by dalang is seen as an entertainment also contain life perceptia, behavior, ethic, norm, character, and life principles. Dalang as an artist alsofunction as educator for the community. In managing and leading leather puppet, he has to be able to apply managementfitnction well in order to performnicely, fluently, and sequencewith the planned, to satisly the audience.

Keywords : Leather puppet, dalang, ethnic, education management

\section{PENDAHULUAN}

Wayang kulit adalah budaya Jawa/Indonesia yang adilubung (benilai tinggi) dan sudah diakui sebagai warisan budaya dunia melalui Unesco PBB yang menyatakan bahwa wayang kulit merupakansalah satu budaya Indonesia yang perlu dilestarikan. Pengakuan tersebut tertuang dalam Surat Keputusan tanggal 7 November2003 (Masterpiese of Oral and Intangible Heritage of Humanity). Dengan adanya pengakuan ini berarti Indonesia mempunyai tanggung jawab untuk selalu berusaha melindungi dan melestarikan budaya wayang kulit tersebut.

Wayang kulit yang dimainkan oleh dalang selain sebagai tontonan dan hiburan juga sarat dengan muatan ajaran kehidupan, tingkah laku, etika, sopan-santun, karakter, dan prinsip hidup. Dalang dalam pementasan wayang kulit selain bertindak sebagai penghibur penonton juga bertindak sebagai pendidik masyarakat penonton. Pendidikan yang dilakukan kepada masyarakat dapat melalui alur cerita, dialog para tokoh cerira,wejangan pendeta kepada satria, maupun melalui humor pada adegan Limbuk,
Cangik (abdi putri yang juga merupakan pelawak) dan adegan gara-gara (adegan paraabdi satria yang juga bertindak sebagai pelawak). Karena dalang dalam pementasan wayang kulit merupakan pendidik masyarakat penonton maka pada pergelaranwayang kulit dalang sebagai pimpinan pergelaran juga perlu memahami dan dapat melaksanakan fungsi-fungsi manajemen pendidikan. Permasalahan yang ada adalah fungsi manajemen apa saja yang dilaksanakan oleh dalang wayang kulit dalam melaksanakan pergelaran wayang kulit semalam suntuk dengan dibantu oleh para pengrawit dan pesinden.

Cukup banyak pakar yang mengemukakan pendapatnya tentang fungsi manajemen, misalnya George R. Tery menyatakan bahwa fungsi manajemen adalah: planning, organizing, actuating, dan controlling; menurut Henry Fayol fungsi manajemen adalah: planning, organizing,commanding, coordinating, dan controlling; menurut Siagian planning, organizing, motivating, dan controlling; Menurut Luther Gullich: planning, organizing, staffing, directing, coordinating, reporting, danbugeting; Menurut William Spilegel: planning, 
organizing, dan controlling; menurut William $\mathrm{H}$. Newman: planning, organizing, staffing, directing, coordinating, dan reporting; menurut Winardi: planning, organizing, coordinating, actuating, communication, dan controlling, menurut John D.Milled: directing, dan facilitating; dan masih banyak lagi pakar rnanajemen yang menyatakan pendapatnya.

Dalam tulisan ini sengaja dibahas fungsi manajemen yang dapat diterapkanoleh dalang dalam rnelaksanakan pergelaran wayang kulit semalam suntuk. Dalang dalam melaksanakan pergelaran wayang kulit selain memberikan hiburan sekaligus mendidik masyarakat pehonton. Pendidikan yang terkandung di dalam pergelaran wayang kulit selain ada dalam setiap adegan juga secara keseluruhan lakon dari awal sampai akhir mempunyai kandungan pendidikan kehidupan yang mencakup hubungan manusia dengan Sang Maha pencipta juga hubungan antar manusia.

Manajemen pendidikan pada pementasan wayang kulit dalang sebagai pimpinan pada pergelaran wayang kulit harus dapat mengelola jalannya pementasan dari persiapan, pelaksanaan, dan akhir pementasan. Dalang merupakan pimpinan pergelaran wayang kulit yang dibantu oleh pengrawit, pesinden, wiraswara/penggerong, bintang tamu pelawak dan atau penyanyi, serta teknisi sound system dan ada juga dalangyang menggunakan jasa penata lampu dan penata slide.

Dalam memimpin dan mengelola pementasan wayang kulit, dalang harus dapat melaksanakan fungsi-fungsi manajemen dengan baik agar pelaksanaanpergelaran wayang kulit berjalan dengan baik, lancar, dan sesuai dengan yang direncanakan sehingga dapat mernuaskan penanggap dan penonton. Fungsi manajemenyang dilaksanakan dalang dalam pergelaranwayang kulit meiiputi: (1) perencanaan(planning), (2) peramalan (fforecasting), (3)pengorganisasian (organiżing),

personalia(staffing),

pengarahan (directing/commanding), (6) pelaksanaan (actuating), (7) koordinasi (coordinating), (8)kepemimpitan (leading), (9) pemotivasian(motivating), dan (10) pengawasan (controlling).

\section{PEMBAHASAN}

\section{Perencanaan (Planning)}

Perencanaan (Planning) adalah fungsi pertama dan utama dari manajemen dan organisasi, dan perencanaan harus dibuat terlebih dulu. Dalam pergelaran wayang kulit perencanaan yang harus disiapkan adalah: (a) lakon atau ceritera, (b)urutan adegan, (c) gending iringan yangdigunakan pada tiap adegan, (d) tokoh yangakan dimunculkan dalam setiap adegan. (e)wejangan atau materi pendidikan masyarakat yang akan disampaikan pada adegan mana saja, (f) sanggit/dramatisasi, (g)tokoh yang akan melakukan peperangan dan tokoh yang menjadi musuhnya, (h)gending dan atau lagu untuk selingan, (i)pembagian waktu tiap adegan, fi) pesinden dan atau penggerong siapa yang sesuai melayani permintaan gending/lagu dari penonton disesuaikan dengan keahlian dan warna suara. yang sesuai dengan lagu tertentu, (k) alokasi waktu yang disediakan 
bila ada pesanan atau permintaan lagu dan atau gending dari para penonton. Dalang harus mematuhi perencanaan yang sudah direncanakan agar pelaksanaan pergelaran wayang kulit dapat lancar dan tidak kedodoran.

\section{a. Perencanaan Iakon atau ceritera}

Lakon yang dipergelarkan dalang wayangkulit dapat atas permintaan penanggap/pemangku hajat, dapat pula pemilihan lakon diserahkan kepada dalang. Biasanya lakon untuk hajat khitanan adalah kelahiran tokoh wayang kulit yang disesuaikan dengan karakter anak yang dikhitan,misalnya bila anaknya pemberani orang tuanya memesan lakon lahirnyaWisanggeni (anak Arjuna dengan BidadaraiBathari Dersanala yang sangat pemberanaidan sakti). Untuk hajat pernikahan biasanya lakon yang dipesan adalah lakon rabine/penikahan tokoh wayang yang sesuai dengan karakter mempelai wanita atau mempelai pria. Misal bila mempelai wanita kembang desa banyak yang menginginkan menikahi, menggunakan lakon Alap-alapan(perebutan putri raja). Setelah menerima pesanan lakon dalang harus merencanakan alur cerita dengan disertai urutan adegan dari awal hingga akhir cerita/lakon.

\section{b. Perencanaan urutan adegan}

Setelah mendapat pesanan lakon dalang perlu membuat perencanaan urutan adegan dan tokoh siapa saja yang dimunculkan dalam setiap adegan. Urutan adegan dalam pewayangan dibagi menjadi tiga bagiansesuai pathet karawitan, yaitu pathet nem,pathet sanga, dan pathet manyura. Urutan adegan yang baku pada pedalangan wayang kulit seperti pada tabel berikut.

Tabel 1

Urutan Adegan Berdasarkan Pathet pada Pergelaran Wayang Kulit Purwa

\begin{tabular}{|c|c|c|c|}
\hline No & Pathet Nem & $\begin{array}{l}\text { Pathet } \\
\text { Sanga }\end{array}$ & $\begin{array}{c}\text { Pathet } \\
\text { Manyur } \\
\text { a }\end{array}$ \\
\hline 1. & Jejer pertama & Gara-gara & $\begin{array}{l}\text { Jejer } \\
\text { Manyura } \\
\text { I }\end{array}$ \\
\hline 2. & $\begin{array}{l}\text { Jengkaran/Bubara } \\
\text { n Pasewakan }\end{array}$ & $\begin{array}{l}\text { Jejer } \\
\text { Pertapan }\end{array}$ & $\begin{array}{l}\text { Perang } \\
\text { Manyura } \\
\text { I }\end{array}$ \\
\hline 3. & Gapuran & $\begin{array}{l}\text { Adegan } \\
\text { Bambanga } \\
n\end{array}$ & $\begin{array}{l}\text { Jejer } \\
\text { Manyura } \\
\text { II }\end{array}$ \\
\hline 4. & Kedhatonan & $\begin{array}{l}\text { Perang } \\
\text { Kembang }\end{array}$ & $\begin{array}{l}\text { Perang } \\
\text { Brubuh }\end{array}$ \\
\hline 5. & Limbuk-Cangik & $\begin{array}{l}\text { Jejer Pathet } \\
\text { Sanga I }\end{array}$ & $\begin{array}{l}\text { Tayunga } \\
\mathrm{n}\end{array}$ \\
\hline 6. & Adegan Padupan & $\begin{array}{l}\text { Perang } \\
\text { Sintren }\end{array}$ & $\begin{array}{l}\text { Jejer } \\
\text { Terakhir }\end{array}$ \\
\hline 7. & Paseban njawi & $\begin{array}{l}\text { Jejer Pathet } \\
\text { Sanga II }\end{array}$ & $\begin{array}{l}\text { Adegan } \\
\text { Golek }\end{array}$ \\
\hline 8. & Budhalan Wadya & $\begin{array}{l}\text { Ngupaya } \\
\text { Sraya }\end{array}$ & $\begin{array}{l}\text { Tancep } \\
\text { Kayon }\end{array}$ \\
\hline 9. & Perang Ampyak & & \\
\hline 10. & $\begin{array}{l}\text { Jejer Sabrang (Jejer } \\
\text { kedua) }\end{array}$ & & \\
\hline 11. & Perang Gagal & & \\
\hline
\end{tabular}


melawan satria berbudi luhur dari kerajaan tanah Jawa.

\section{e. Perencanaan Sanggit/dramatisasi}

Sanggit/dramatisasi perlu direncanakan dalang wayang kulit untuk menghidupkan lakon/cerita, sehingga penonton dapat terharu, kasihan, geregetan,dan sebagainya. Misalnya sanggit yang dibuat almarhum Ki Nartosabadho padaepos Ramayana. Pada cerita baku Kumbakumbadan Aswanikumba keduanya adalah anak kembar Kumbakarna maju perang dulu rnelawan tetntara kera Ramawatjaya dan keduanya gugur di medan laga, setelah itu Rahwana memerintahkan Kumbakarna untuk maju kemedan perang. Ki Nartosabdho membuat sanggit Kumbakarna yang maju perang dan gugur, baru kedua anaknya maju berperang dengan alasan meneruskan perjuangan bapaknya/orangtuanya/generasi tua dalam membela negara Alengka dan buka membela Rahwana rajanya yang angkaramurka.

\section{f. Perencanaan Wejangan atau MateriPendidikan Masyarakat}

Wejangan yang biasanya dilaksanakan pada adegan Pendeta dipertapaan yang dihadap satria yang merupakan cucunya, selain disesuaikan dengan kebutuhan adegan dan lakon juga dapat diselipkan pendidikan kepada masyarakat penonton yang berkaitan rasa kebangsaan/nasionalisme, kebersihan lingkungan, pentingnya pendidikan, ajaran spiritual dan sebagainya.Wejangan juga dapat dilaksanakan oleh abdi panakawan kepada satria asuhannya dengan disesuaikan konteks alur cerita.

\section{g. Perencanaan Tokoh yang Akan Melakukan Peperangan}

Perencanaan tokoh yang melakukan peperanganatau Perang tanding ini perencanaannya adalah tokoh yang serius diperangkan dengan tokoh serius, tokoh gagah diperangkan dengan tokoh gagah, tokoh berkarakter halus diperangkan dengan tokoh berkarakter halus, tokoh gecul/lucu diperangkan dengantokoh gecul. Selain itu pada perang kembang(perang untuk penghias setiap lakon)satria selalu diperangkan dengan raksasa Cakil dan raksasa teman Cakil. Ada juga perang sesuai tuntutan lakon satria yang berperang melawan raja raksasa untuk menghancurkan raja angkara murka misalnya Rama melawan Rahwana, Arjuna melawan raja raksasa Niwatakawaca, dansebagainya.

\section{h. Perencanaan Gending dan atau Lagu} untuk Selingan

Gending atau lagu selingan biasanya dipesan penonton pada waktu adeganLimbukCangik dan Gara-gara. Dalang harusdapat membatasi pesanan lagu agar tidak kehabisan waktu untuk menyelesaikan alur cerita. Pembatasan waktu tersebut dapat berdasarkan jumlah lagu dan atau berdasarkan waktu yang disediakan untuk itu. Agar tidak mengecewakan penonton dan pemesan lagu, dalang harus dapat mensiasati pesanan lagu yang sama atau hampir sama pesanan beberapa pemesan digabungkan 
menjadi satu, dengan demikian dapat menghemat waktu tanpa mengecewakan pemesan lagu.

\section{i. Perencanaan Pembagian Waktu} Setiap Adegan

Dalang harus dapat merencanakan pengelolaan waktu dalam melaksanakan pergelaran wayang kulit semalam suntuk. Waktu yang tersedia kurang lebih 7 sampai 8 jam, dimulai dari pukul 21.00 malam sampai sebelum subuh sekitar pukul 04.00 atau 05.00. Bila dalang tidak dapat mengelola pembagian waktu alur cerita yang dipergelarkan tentu kedodoran, danhal ini sangat mengurangi keindahan pergelaran.

\section{j. Pesinden dan atau Penggerong yang} Melayani Permintaan Gending/lagu

Dalang harus memahami potensi dan keahlian pesindennya dalam membawakan lagu, siapa yang mempunyai keahlian melantunkan sindenan gending, lagu dolanan, lagu campursari, maupun lagu-lagu daerah. Dengan demikian dalang dapat menugasi masing-masing individu pesinden dalam mengiringi pergelaran maupun melayani pesanan lagu dari penonton.

\section{k. Alokasi Waktu yang Disediakan untuk Melayani}

\section{Lagu/gending}

Dalang juga harus mernpunyai perencanaan waktu yang dialokasikan khusus untuk melayani pesanan lagu/gending dari penonton. Jangan sampai waktu yang digunakan untuk melayani pesanan lagu melebihi yang digunakan untuk menggarap lakon. Hal ini karena yang ditanggap oleh pemangku hajat adalah wayang kulit bukan campursarinya. Hal ini sesuai dengan yang dinyatakan oleh dalang Jogjakarta almarhum Ki Tumbul Hadiprayitno, kalau dalam pergelaran wayang kulit pesanan lagu campursari terlalu banyak dan menyita waktu untuk garapan lakon, ya jangan menanggap wayang kulit nanggap saja campursari. Kalau memang berniat menanggap wayang kulit selingan lagu campursarinya saja sekedar untuk pemanis pergelaran.

\section{Peramalan (Forecasting)}

Peramalan (Forecasting) merupakan kegiatan meramal dan atau memperki-rakan berbagai kemungkinan yang akan terjadi pada saat pergelaran wayang kulit dilaksanakan. Misalnya pada waktu adegan Limbuk-Cangik dan Garagara diramalkan tentu ada yang minta gending dan lagu-lagu dari penonton. Untuk itu dalam perencanaan harus ada pembatasan waktu yang disediakan untuk melayani permintaan gending dan lagu dari penonton agar tidak berlarut-larut sehingga jalannya pergelaran masih tetap lancar sesuai dengan perencanaan. Selain itu juga perlu disediakan wayang cadangan bagi tokoh bila sewaktu-waktu ada sambungan tangan yang lepas dan kerusakan lain sehingga dapat digunakan wayang cadangan.

\section{Pengorganisasian (Organizing)}

Pengorganisasian (Organizing), fungsi pengorganisasian adalah agar memungkinkan 
kegiatan organisasi dapat terlaksana dengan baik. Dalam pergelaran wayang kulit adalah pengorganisasian pengrawit, penggerong (wiraswara) dan pesindenyang akan mengiringi pelaksanaan pergelaran wayang kulit yang dilaksanakan oleh dalang. Para pengrawit, penggerong dan pesinden harus selalu kompak dalam melaksanakan iringan pergelaran wayang kulit sesuai dengan perencanaan yang sudah disepakati bersama dengan dalang.

\section{Personalia (Staffing)}

Personalia (Staffing) adalah fungsi dan upaya manajemen untuk merekrut tenaga kerja yang professional untuk ditempatkan pada bidang yang sesuai dengan keahliannya sehingga setiap tenaga kerja dapat bekerja dan berkreasi, berekspresi, berinovasi secara maksimal untuk menyelesaikan pekerjaan tepat pada waktunya demi kehidupan organisasi. Dalam pergelaran ivayang kulit para pengrawit harus ditempatkan sesuai dengan keahliannya. Misainya yang ahli memaikan kendang harus diberi tugas memamaikan kendang, ahli bonang harus ditugasi memaikan bonang, ahli dalam memaikan kenong harus ditempatkan sebagai pemain kenong, demikian juga penempatan yanglain harus sesuai dengan keahliannya.Kalau ada yang mempunyai keahlian rangkap dan harus bertugas rangkap perlu disesuaikan penempatannya agar tidak sampai memainkan kedua instrumen gamelan yang dikuasai secara bersamaan.

Misalnya yang mempunyai keahlian memainkan saron atau demung dapat merangkap memainkan suling atau rebab, sebab bila suling, atau rebab sedang dimaikan instrumen saron atau demung tidak dimaikan. Karena gender, gambang, kenong, dan gong selalu ikut dimainkan bila suling dan rebab dimainkan, maka pemain instrumen gender, gambang, kenong, dan gong tidak dapat merangkap memaikan suling dan atau rebab. Demikian juga para pesinden yang ahli menyindeni gending diberi tugas menyindeni gending, sedangkan yang ahli melantunkan lagu dolanan juga harus ditugasi melantunkan lagu dolanan. Dengan menempatkan personal sesuai dengan keahliannya maka pergelaran wayang kulit akan dapat berjalan dengan lancar sesuai perencanaan, dan diharapkan dapat memuaskan penanggap dan penonton.

\section{Pengarahan (Directing/Commanding)}

Pengarahan (Directing/Commanding), untuk menghindari adanya keragu-raguan dalam melaksanakan tugas, para pengrawit, penggerong, pesinden, dan atau bintang tamu pelawak atau penyanyi harus diberikan arahan-arahan atau petunjuk-petunjuk pelaksanaan sesuai keinginan dalang dalam melaksanakan pergelaran wayang kulit. Misalnya pelaksanaan sumuk gropak (iringan berhenti mendadak), pindah irama dari irama satu ke irama rangkap, dan sebagainya.

Pesinden dalam melantunkan lagu tertentu perlu ada bawa (lagu pembuka) atau tidak, dan sebagainya. Pengrahan dapat dilaksanakan secara umum sebelum pergelaran dimulai, tetapi tidak menutup kemungkinan arahan dilaksanakan di tengah-tengah pelaksananaan pergelaran wayang 
kulit. Dalam hal ini dalang dituntut dapat bertindak sebagai pemimpin yang arif-bijaksana dan kreatif.

Dalang dalam meminta gending kepada pengrawit tidak langsung menyebutkan minta gending ini atau itu, tetapi mempunyai cara tertentu yang lebih halus dan bagi penonton awam tidak dapat memahami bahwa dalang meminta gending tertentu untuk mengiringi adegan tertentu. Sebagai contoh pada saat adegan selesai jejer portama di kayangan Jonggring Salaka, dalang mengucapkan sebagai berikut. Hanenggih wan kocapa, purna wedharing wasita, Sang Hyang Jagat Pratingkah arsa kundur Makayangan Purantara. Yekti hanetepi deniraju meneng Narendraning para dewa, tubu kang kaweca dadya, medharsabda sapisan dadi tan kena owah gingsir. Mangkana Sang Hyang Jagat Girinata sigra kundur Makayanganden ayap para widadari, tinon sakingmandrawa kadi "mawarna-warna busanane".

Ternyata ucapan dalang yang terakhir (mawarna-warna busanane) merupakan sasmita/kode dalang untuk meminta gending Puspawarna untuk mengiringi adegan Bathara Guru selesai mengadakan pertemuan di balairung. Di sini tampak bahwa dalang dalam meminta gending kepada pengrawit tidak menggunakan kata-kata langsung meminta, tetapi menggunakan bahasa terselubung dengan kata-kata yang mempunyai ucapan mirip gending yang diminta. Hal ini merupakan cara ke tujuan tertentu yang lebih halus sehingga tidak merusak keindahan pakeliran.

Dalam pergelaran wayang kulit ada istilah dhodhogan. Yang dimaksud dhodhogan adalah pukulan cempala kekotak atau dapat disertai/disusul dengan keprakan yang merupakan kode/sasmita dalang kepada para pengrawit. Fungsi dhodhogan adalah sebagai tertera pada tabelberikut.

Tabel 2

Bunyi dan Fungsi Dhodhogan Kothak yang Dibunyikan Dalang

\begin{tabular}{|c|c|c|}
\hline $\mathrm{O}$ & $\begin{array}{c}\text { JENIS } \\
\text { DHODHOGA } \\
\mathrm{N}\end{array}$ & FUNGSI \\
\hline 1. & $\begin{array}{l}\text { Dhodhogan } \\
\text { Lamba }\end{array}$ & $\begin{array}{lr}\text { Untuk sasmita patetan } \\
\text { atau untuk } & \text { sela/jedah } \\
\text { monolog } & \text { tokoh } \\
\text { wayang. } & \text { Suaranya: } \\
\text { Dhog. } & \end{array}$ \\
\hline 2. & $\begin{array}{l}\text { Dhodhogan Pinjal } \\
\text { Lamba }\end{array}$ & $\begin{array}{l}\text { Untuk permintaan } \\
\text { srepeg. Suaranya: } \\
\text { Dhog-dhog, dhog- } \\
\text { dhog, dhog-dhog, } \\
\text { disambung keprak crek- } \\
\text { crek-crek dst. }\end{array}$ \\
\hline 3. & $\begin{array}{l}\text { Dhodhogan } \\
\text { Singgetan }\end{array}$ & $\begin{array}{l}\text { Untuk tanda jedah } \\
\text { pocapan (cerita) dalang. } \\
\text { Suaranya: Dherodhog- } \\
\text { dhog. }\end{array}$ \\
\hline 4. & $\begin{array}{l}\text { Dhodhogan Pada } \\
\text { Wacana }\end{array}$ & $\begin{array}{l}\text { Untuk memberi tanda } \\
\text { antara ucapan tokoh } \\
\text { wayang satu dengan } \\
\text { tokoh lain dalam } \\
\text { antawacana (dialog). } \\
\text { Suaranya: Dhog, } \\
\text { Dherodhog-dhog. }\end{array}$ \\
\hline 5. & Dhodhogan Neter & Untuk menandakan \\
\hline
\end{tabular}




\begin{tabular}{|c|c|c|}
\hline & & $\begin{array}{l}\text { suasana tegang/ marah. } \\
\text { Suaranya: Dherodhog- } \\
\text { dhog, dhog- dhog- } \\
\text { dhog-dhog-.........dst. }\end{array}$ \\
\hline 6. & $\begin{array}{l}\text { Dhodhogan } \\
\text { Panggugah }\end{array}$ & $\begin{array}{l}\text { Untuk tanda bahwa } \\
\text { dialog sudah mulai } \\
\text { memanas, biasanya } \\
\text { dilanjutkan dengan } \\
\text { adegan perang. } \\
\text { Suaranya: Dhog, dhog, } \\
\text { dhog, ..dst. }\end{array}$ \\
\hline 7. & $\begin{array}{l}\text { Dhodhogan } \\
\text { Sendhalan }\end{array}$ & $\begin{array}{l}\text { Untuk tanda gamelan } \\
\text { dibunyikan sampak. } \\
\text { Suaranya: Dhog-dhog- } \\
\text { dhog..disambut dengan } \\
\text { keprak crek-crek-crek } \\
\text { dst. }\end{array}$ \\
\hline 8. & $\begin{array}{l}\text { Dhodhogan } \\
\text { sumeleb }\end{array}$ & $\begin{array}{l}\text { Untuk memberi tanda } \\
\text { agar gamelan di } \\
\text { bunyikan ayak-ayak. } \\
\text { Suaranya: } \\
\text { dhog,..dhog,..dhog,..dh } \\
\text { og, ..dhog. }\end{array}$ \\
\hline
\end{tabular}

\section{Pelaksanaan (Actuating)}

Pelaksanaan (Actuating) merupakanfungsi manajemen yang mencakup fungsi-fungsi manajemen perencanaan, pengorganisasian, personalian,pengarah-an, kepemimpinan, koordinasi, pemotivasian, dan pengawasan.
Pelaksanaan adalah upaya manajemen untuk mengerahkan dan memanfaatkansemua sumber daya organisasi secara efektif dan efisien demi tercapainya tujuan organisasi. Dalam pergelaran wayang kulit pelaksanaannya pada saat pergelaran berlangsung, semua sumberdaya yang ada harus dapat bekerja sebaik mungkin demi suksesnya pergelaranwayang kulit yang dilaksanakan oleh dalang dan dipimpin oleh dalang.

\section{Koordinasi (Coordinating)}

Koordinasi (Coordinating), fungsikoordinasi adalah usaha manajemen untuk menghubungkan, menyelaraskan, dan menyatukan persepsi dan langkah kerja berbagai pekerjaan yang berbeda tetapi mempunyai tujuan yang sama yaitu suksesnya pergelaran wayang kulit. Pelaksanaan koordinasi antara para pengrawit, pesinden, penggerong, dan pekerja teknik pendukung pergelaran wayang kulit seperti penata lampu, penata suara, membantu dalang, dapat dilakukan dengan pemberian penjelasan, bimbingan, nasihat, arahan, petunjuk, instruksi atau perintah, dan bahkan dapat berupa teguran atau peringatan oleh dalang. Dalang dalam melaksanakan koordinasi dapat dilaksanakan sebelum pergegelaran dimulai, pada waktu pelaksanaan pergelaran, dan setelah selesai melaksanakan pergelaran dengan harapan pergelaran berikutnya agar lebih baik lagi.

\section{Kepemimpinan (Leading)}

Kepemimpinan (leading), adalah upaya mencapai tujuan pergelaran wayang kulit yang 
merupakan kerjasama dari sumberdaya yang ada dalam organisasi pergelaran wayang kulit. Pergelaran wayang kulit tidak akan berhasil baik sesuai dengan tujuan bila tidak didukung oleh aktivitas kepemimpinan. Dalam pergelaran wayang kulit pimpinan utama adalah dalang. Kepemimpinan dalang dalam mengelola pergelaran wayang kulita dalah kepemimpinan transaksional, transfonnasional, dan situasional. Kepemimpinan transaksional dilaksanakan bila parapengrawit dan pesinden yang pengiringi pergelaran wayang kulit bukan satu organisasi dengan dalang. Dalang sebagai pemimpin pergelaran wayang kulit yang mendesain urutan adegan dan gending iringan, sedangkan pengrawit dan pesinden yang melaksanakan desaian tersebut. Bila pengrawit dan pesinden merasa belum mampu melaksanakan garapan gending tertentu, maka dapat diternpuh jalan tengah dengan cara diadakan gending pengganti yang mampu dilaksanakan oleh pengrawit dan pesinden dengan tujuan pergelaran tetap berjalan dengan lancar dan sukses.

Kepemimpinan trasformasional adalah kemampuan pemimpin untuk dapat melaksanakan pekejaan melalui orang lain untuk mengoptimalkan segala sumber daya organisasi agar dapat mencapai target yang telah ditentukan. Dalam hal ini dalang menyerahkan sepenuhnya kepada pimpinan karawitan untuk mengiringi pergelaran wayang kulit dengan harapan pergelaran wayang kulit yang dilaksanakan dapat berjalandengan lancar dan sukses.
Kepemimpinan situasional yaitu kepemimpinan yang dilaksanakan sesuai dengan situasi yang ada, sehingga tujuan dapat tercapai dalam keadaan atau situasi apapun. Dalam pergelaran wayang kulit dalang juga harus menerapkan kepemimpinan situasional. Dalang harus dapat membaca situasi pada saat pergelaran wayang kulit berlangsung. Misalnya bila permintaan atau pesanan gending dan atau lagu cukup banyak, bagaimana mengajak pengrawit dan pesinden menggabung permintaan/pesanan agar jalannya pergelaran tetap lancar dan sukses tanpa mengecewakan penonton yang memesan lagu/gending maupun penonton yang benar-benar ingin menikmati alur lakon dengan penuh perhatian.

\section{Pemotivasian (Motivating)}

Pemotivasian (Motivating) adalah fungsi manajemen yang digunakan pimpinan agar karyawan mau bekerja dengan segenap daya upayanya agar fujuan dapat tercapai. Pimpinan dapat memotivasibawahan dengan berbagai sudut pandang dan berbagai cara, disesuaikan dengan pola pandang dan pola hidup bawahan. Menurut teori motivasi McGregor yang dikenal dengan teori $\mathrm{x}$ dan $\mathrm{y}$, menurut teori $\mathrm{x}$ pada dasarnya semua manusia adalah malas sehingga harus selalu dikontrol dan diawasi. Menurut teori y ada juga bawahan yang meskipun tidak diawasi tetapi selalu bekerja dengan penuh sernangat, tekun dan penuh rasa tanggung jawab. Dalang biasanya memotivasi pengrawit, penggerong, dan pesinden dengan melalui sendagurau lewat adegan lawakan Limbuk-Cangik dan 
Gara-gara, dengan mengatakan bahwa bagi dan pendidik masyarakat penonton dalam pengrawit, penggerong, dan pesinden memimpin dan mengelola pementasan wayang yangmelaksanakan tugas dengan baik maka kulit, harus dapat melaksanakan fungsi-fungsi honorariumnya akan ditambah.

\section{Pengawasan (Controlling)}

Pengawasan (Controlling), menurut Siagian (1997), pengawasan adalah proses pengamatan kepada seluruh aktivitas organisasi untuk menjamin agar segala aktivitas yang sedang dilaksanakan berjalan sesuai dengan rencana yang telah ditetapkan. Dalang dalam memimpin dan mengendalikan jalannya pergelaran wayang kulit selalu mengadakan pengawasan kepada para pengrawit, penggerong, pesinden, dan juga bintang tamu penyanyi maupun pelawak. yang diadakan pengawasan meliputi pengawasan pelaksanaan perencanaan pembagian waktu, pengawasan lagu yang dilantunkan, pengawasan tindakan atau tingkah-laku dalam melaksanakan tugas.

Pelaksanaan pengawasan dapat melalui dialog langsung dalang dengan pesinden maupun bintang tamu pelawak dan atau penyanyi. Pengawasan para pengrawit melalui kode perintah minta gending dengan kode sasmita gending maupun buka celuk, pergantian irama, dan atau keras lunaknyapukulan gamelan dengan dhodhogan maupun keprakaan. Jadi pengrawit harus selalu siap melaksanakan tugas sesuai perintah maupun perrnintaan dalang.

\section{PENUTUP}

Berdasarkan uraian di atas, maka dapat disimpulkan bahwa dalang sebagai penghibur manajemen dengan baik agar pelaksanaan pergelaran wayang kulit berjalan dengan baik, lancar, dan sesuai dengan yang direncanakan sehingga dapat memuaskan penanggap dan penonton. Fungsi manajerien yang dilaksanakan dalang dalam pergelaran wayang kulit meliputi: (1) perencanaan(planning), (2) peramalan (forecasting),(3) pengorganisasian (organizing), (4) personalia(staffing), (5) pengarahan (directing/commanding), (6) pelaksanaat (actuating), (7) koordinasi (coordinating), (8)kepemimpinan (leading). (9) pemotivasian(motivating), dan (10) pengawasan (controlling).

Dengan demikian disarankan agarpara dalang agar dapat melaksanakan tugasnya memimpin dan mengelola pementasan wayang kulit, di samping menguasai teknik pakeliran dengan baik juga harus memahami dan dapat melaksanakan fungsi-fungsi manajemen.

\section{DAFTAR PUSTAKA}

Dwidjowinoto, Wahjudhi. 1996. Pewayangan.Surabaya: FFBS IKIP Surubaya.

Dwidjowinoto, Wahjudhi.

2005. AnalisisDomain dalam PenelitianKualitatif. Makalah disampaikanpada Seminar JurusanSendratasik FBS Unesa tarlggal30 Desember 2005.

Jarianto.

2006. Kebijakan Budaya padaMasa Orde Baru dan PascaOrde Baru. Jernber:Kompyawisda.

Soenarjo. 
2006. Mencari Jalan untuk Bertabantentang
Wayang, Dalangdan
Jember:Kompyawisda.

Sofyandi, Herman.

2008. Manajemen SumberDaya Manusia. Jogjakarta:Graha Ilmu.

Sukarno.

1992. Dasar-dasar Manajemen.Bandung: Mandar Maju.

Sulistyorini.

2009. Manajemen PendidikanIslam Konsep, Strarcgi danAplikasi. Jogjakarta: Teras.

Werang, Basilius Redan.

2009. Manajemen danEkonomi Sumber daya Manusia.Malang: Elang Mas.

Siregar, Ali Basyah dan Samadhi, TMAAri.

1988. Manajemen.Bandung: Institut Teknologi

Bandung. 